\title{
Representatividade importa: um relato de experiência sobre o PIBID e as contribuições do letramento racial crítico para o ensino de inglês
}

\author{
Representation matters: an experience report on PIBID and the contributions of \\ critical racial literacy to the teaching of English
}

\author{
Gabriela da Silva Pires ${ }^{1}$, Hilen Pulinho Alves ${ }^{2}$, Rafael Macário Fernandes ${ }^{3}$
}

\begin{abstract}
RESUMO: Este relato, desenvolvido por um grupo de estudantes da Universidade Federal de Viçosa (UFV) - bolsistas do Programa Institucional de Bolsas de Iniciação à Docência (PIBID) baseou-se em uma aula de língua inglesa ministrada em uma escola da rede pública da cidade de Viçosa/MG. Nossa aula teve como foco a prática do letramento racial crítico (LRC) sob a luz da representatividade negra na mídia. Para isso, baseamo-nos nos estudos de Ferreira $(2014,2018)$ e Santos (2020). Fazendo uso de materiais diversificados e priorizando a comunicação oral, objetivamos contribuir para a formação sociocrítica dos alunos através do ensino da língua estrangeria. Dentre as discussões apresentadas neste relato, destacam-se a produtividade do LRC como abordagem pedagógica que proporciona visibilidade e diversidade no ambiente escolar ao mesmo tempo em que desconstrói pensamentos racistas, e a importância de se trabalhar a representatividade na mídia como forma de questionar representações estereotipadas que acarretam a internalização de práticas preconceituosas. Na parte final do trabalho, apontamos para, dentre outras questões, a relevância de práticas educacionais que possibilitem o exercício da cidadania em sala de aula e que promovam a conscientização acerca da multiplicidade racial e cultural humana entre os estudantes.
\end{abstract}

PALAVRAS-CHAVE: representatividade; letramento racial crítico; ensino de inglês.

ABSTRACT: This report, developed by a group of students from the Federal University of Viçosa (UFV) - scholarship holders of the Institutional Program for Teaching Initiation Scholarships (PIBID) - was based on an English lesson given at a public school in the city of Viçosa/MG. Our class focused on the practice of critical racial literacy (CRL) considering black representation in the media. To this end, we relied on the studies of Ferreira $(2014,2018)$ and Santos (2020). By using diverse materials and prioritizing oral communication, we aimed to contribute to the socio-critical education of our learners through the teaching of a foreign language. Among the discussions presented in this report, the productivity of CRL stands out as a pedagogical approach that provides visibility and diversity in the school environment while deconstructing racist thoughts and the importance of using representation in the media as a way of questioning stereotyped portrayals that lead to the internalization of prejudiced practices. At the end of our work, we point out, among other issues, the relevance of educational practices that enable the exercise of citizenship in the classroom and promote awareness about human racial and cultural multiplicity among students.

\footnotetext{
${ }^{1}$ Professora Adjunta do Departamento de Letras da Universidade Federal de Viçosa (UFV), Doutora em Linguística. Viçosa/MG. Brasil. ORCID id: 0000-0003-4292-2700. E-mail: gabriela.pires@ufv.br

${ }^{2}$ Graduando em Letras - Português/Inglês pela Universidade Federal de Viçosa (UFV) e bolsista de Iniciação Científica PIBIC/CNPq edital 2019/2020. ORCID id: 0000-0002-7892-9683. E-mail: hilen.alves@ufv.br

${ }^{3}$ Graduando em Letras - Português/Inglês pela Universidade Federal de Viçosa (UFV) e bolsista de Iniciação Científica PIBIC/CNPq, editais 2019/2020 e 2020/2021. ORCID id: 0000-0002-6742-3206. E-mail: rafael.macario@ufv.br Agradecimentos à CAPES pela bolsa concedida.
} 
KEYWORDS: representation; critical racial literacy; English teaching.

\section{INTRODUÇÃO}

O presente trabalho caracteriza-se como um relato de experiência vivenciada por uma equipe de estudantes, graduandos em Letras, com habilitação em Português/Inglês, e bolsistas do Programa Institucional de Bolsas de Iniciação à Docência (doravante, PIBID) - subprojeto de língua inglesa - da Universidade Federal de Viçosa (UFV). O PIBID é um programa do Ministério da Educação que promove a inserção de licenciandos na rede pública com o objetivo de melhorar a qualidade da educação básica e estreitar as relações entre a escola e a universidade.

A relevância deste relato reside em divulgar o caráter interdisciplinar do PIBID, que estimula, entre outras formas de intervenção, a realização de experiências didáticas que promovam conscientização, principalmente no que concerne a problemáticas sociais que também atravessam o contexto escolar, como é o caso da desigualdade racial. Desta forma, acreditamos que nosso trabalho, além de ajudar a divulgar uma visão de educação progressista, pautada na inclusão e na reflexão sociocrítica, possa também auxiliar professores - orientadores e supervisores de estágio - a repensar as formas de atuação de seus estagiários nas escolas.

A partir do ensino de vocabulário e de expressões idiomáticas, objetivamos proporcionar a uma turma de alunos da rede estadual a oportunidade de utilizar a língua alvo de forma mais significativa, promovendo debates sobre questões fundamentais, como a importância da representatividade na mídia. Além disso, com o intuito de contribuir para a formação de cidadãos críticos a respeito das implicações sociais do racismo, esperamos que a aula temática discutida neste trabalho possa corroborar a desconstrução dessa forma de preconceito no ambiente escolar.

Para a elaboração da aula, a equipe atentou-se à utilização de materiais autênticos e de livre acesso na internet, como vídeos e um texto na língua alvo. Ademais, buscamos desenvolver uma aula de língua estrangeira mais lúdica e interativa, adicionando elementos da cultura pop, como filmes e séries mainstream, e promovendo o posicionamento dos alunos através da realização de uma dinâmica. Consideramos importante ressaltar também que nos ativemos à pesquisa bibliográfica e à adequação do tema da aula aos parâmetros curriculares educacionais.

Como aporte teórico, baseamo-nos nos estudos sobre representatividade e letramento racial crítico (LRC), de Ferreira $(2014,2018)$ e Santos (2020), além da concepção de uma educação crítica, segundo a BNCC, e do ensino de cultura afro-brasileira, segundo a Lei 10.639/03. Desta maneira, na seção 2, comentamos a questão racial sob a luz dos documentos norteadores e discutimos os conceitos centrais do trabalho aplicados ao ensino de línguas. Na seção 3, 
descrevemos a proposta de intervenção, suas etapas e aplicação. Na seção 4, refletimos sobre os resultados obtidos e suas contribuições para a prática docente. E, por fim, na seção 5, apontamos algumas considerações finais sobre o trabalho.

\section{REVISÃO DE LITERATURA}

\subsection{SOBRE O RACISMO E A AULA DE LÍNGUA INGLESA: O QUE DIZEM AS DIRETRIZES CURRICULARES NACIONAIS (DCNs)?}

A Base Nacional Curricular Comum (doravante, BNCC) é um documento normativo que prescreve determinados conhecimentos, competências e habilidades que devem ser desenvolvidos ao longo dos anos da Educação Básica. No contexto escolar, a BNCC é tida como documento norteador para a construção dos currículos das escolas públicas e privadas de todo o Brasil, tendo como propósito a formação humana integral e a construção de uma sociedade justa, democrática e inclusiva (BRASIL, 2018). A BNCC demanda aos currículos - e, consequentemente, requisita aos educadores - uma educação atenta às pluralidades socioculturais presentes na contemporaneidade.

Quanto ao ensino de inglês, o documento pontua que um dos principais intuitos das aulas da língua estrangeira deve ser o de "[...] possibilitar aos estudantes cooperar e compartilhar informações e conhecimentos por meio da língua inglesa" (BRASIL, 2018, p. 485, grifo nosso). Desta forma, a BNCC direciona as aulas da inglês para além da proficiência linguística - formando estudantes não somente capazes de compreender e se comunicar no idioma estrangeiro -, mas, principalmente, cidadãos que possam "[...] agir e posicionar-se criticamente na sociedade, em âmbito local e global" (BRASIL, 2018, p. 485).

Além disso, a Lei 10.639/03, que altera a antiga Lei de Diretrizes e Bases (LDB) de 1996, visando mitigar o racismo edificado há séculos no ambiente escolar, tornou obrigatória a inclusão, no âmbito de todo o currículo escolar básico, de estudos afro-brasileiros como a "[...] História da África e dos Africanos, a luta dos negros no Brasil, a cultura negra brasileira e o negro na formação da sociedade nacional, resgatando a contribuição do povo negro nas áreas social, econômica e política pertinentes à História do Brasil", em especial "[...] nas áreas de Educação Artística e de Literatura e História Brasileiras" (BRASIL, 2003).

\subsection{O LETRAMENTO RACIAL CRÍTICO E O ENSINO DE LÍNGUAS}


Por letramento racial crítico (doravante, LRC), entende-se uma abordagem que permite “[...] uma compreensão poderosa e complexa da forma como a raça influencia as experiências sociais, econômicas, políticas e educacionais dos indivíduos e dos grupos" (SKERRETT, 2011 apud FERREIRA, 2014, p. 250). Segundo Almeida (2017 apud SANTOS, 2020), o LRC nos leva a refletir sobre o lugar do negro na sociedade, evidenciando a desconstrução de práticas naturalizadas, como a preponderância do pensamento eurocêntrico. Ademais, o LRC, nas palavras de Guinier (2004 apud FERREIRA, 2014), guia-nos a repensar a raça como um instrumento de controle social, geográfico e econômico. Com efeito, essa abordagem, segundo Almeida (2017 apud SANTOS, 2020), reflete a racialização das relações, que estabelece arbitrariamente direitos e lugares hierarquicamente diferentes para brancos e não-brancos, legitimando uma suposta hegemonia branca.

Quando aplicado ao ensino de língua, seja materna ou estrangeira, o LRC cumpre os termos propostos pela BNCC e pela Lei 10.639/03, pois, sendo a língua uma ferramenta sociocultural para comunicar significado e performar a identidade (SKERRETT, 2011 apud FERREIRA, 2018), o ensino linguístico crítico possibilita aos estudantes não apenas seu uso para termos individuais e pessoais, mas também para termos coletivos que os permitem posicionar-se frente ao mundo de forma esclarecida, desconstruída, atenta e tolerante às relações socioculturais e étnico-raciais. Outrossim, nas aulas de língua, o LRC prioriza a relevância social do aprendizado, pois sua aplicação visa a promoção da igualdade racial e eliminação de formas de discriminação e opressão, tanto individual como institucional (TROYNA et CARRINGTON, 1990 apud SANTOS, 2020).

\subsection{A REPRESENTATIVIDADE COMO UM TEMA DE AULA DE LÍNGUA INGLESA}

A educação sociocrítica visada pela BNCC e pela Lei 10.639/03 concretizar-se-á através de recursos e escolhas didático-pedagógicas que refletirão o propósito do educador ao planejar suas aulas. Desta maneira, a abordagem do LRC, como prática educacional centrada nas dinâmicas étnico-raciais, pode ser explorada de diferentes formas, a depender da disciplina, do contexto sociocultural escolar, dos recursos didáticos disponíveis, entre outros fatores.

Para a nossa aula temática, em função da faixa etária e do perfil dos alunos, a representatividade mostrou-se um tópico pertinente e atual por meio do qual poderíamos incitar uma discussão racial, além do ensino linguístico. Ademais, a relevância desse tema sustenta-se na realidade de vulnerabilidade social e racial dos alunos autodeclarados negros das escolas públicas brasileiras, que, além de constituírem número considerável dos matriculados nessas instituições, 
segundo estudo da Unicef, somaram 48,41\% dos estudantes reprovados só no ano de 2019 número duas vezes maior do que o de brancos, segundo o mesmo estudo.

Por representatividade, entende-se a expressão dos interesses de um grupo por meio de uma figura representante que fala coletivamente e posiciona-se socialmente comprometida com as demandas e necessidades de seus representados. A representatividade caracteriza-se, portanto, como um retrato da subjetividade e da identidade dos indivíduos que integram um determinado grupo. Nas artes e na mídia, a representatividade prioriza a pluralidade em detrimento de visões estereotipadas ou arquetípicas para que, dessa forma, o imaginário coletivo seja reconstruído com mais variedade (ANDRADE, 2020).

$\mathrm{O}$ trabalho da representatividade nas aulas de língua inglesa mostra-se muito produtivo às práticas de LRC, pois exalta a diversidade, assegurando visibilidade às características e relações sociais de grupos historicamente discriminados através do ensino da língua estrangeira. As dinâmicas identitárias explicitadas pela representatividade de diferentes etnias na mídia, quando trabalhadas na sala de aula, criam um caminho para a naturalização e a difusão de uma multiplicidade étnico-racial, contribuindo para a garantia e a defesa da diferença, da diversidade e da pluralidade política, social e cultural (ANDRADE, 2020).

\section{A PROPOSTA DE INTERVENÇÃO}

Nossa aula foi ministrada em dezembro de 2018, em uma turma da $3^{\text {a }}$ série do Ensino Médio, composta por 15 alunos, de uma escola pública estadual da cidade de Viçosa, Minas Gerais. Com duração de 50 minutos, a proposta foi dividida em quatro momentos: um warm-up, uma parte teórica discursiva, um vídeo para reflexão e uma dinâmica. Para isso, utilizamos uma apresentação de slides.

Como toda aula de linguagens, nosso objetivo central foi o aprendizado do inglês e, para tanto, os alunos foram estimulados a se comunicar na língua alvo a todo momento. No entanto, vale ressaltar que a equipe deixou os estudantes livres para utilizar o português caso necessário, sendo algumas vezes ajudados pelos instrutores a construir suas ideias no idioma estrangeiro.

\subsection{CONTEXTUALIZANDO A AULA PELO UNIVERSO DOS SUPER-HERÓIS}

No primeiro momento, com o intuito de introduzir o tema da aula de forma indutiva e divertida, foi feito um warm-up composto por imagens e perguntas sobre a temática dos super- 
heróis através das quais os estudantes tiveram que discutir, em grupos, a respeito das características de seus heróis favoritos, além de refletir sobre a função social desses personagens, como ilustrado abaixo:

Figura 1 - Warm-up sobre super-heróis.

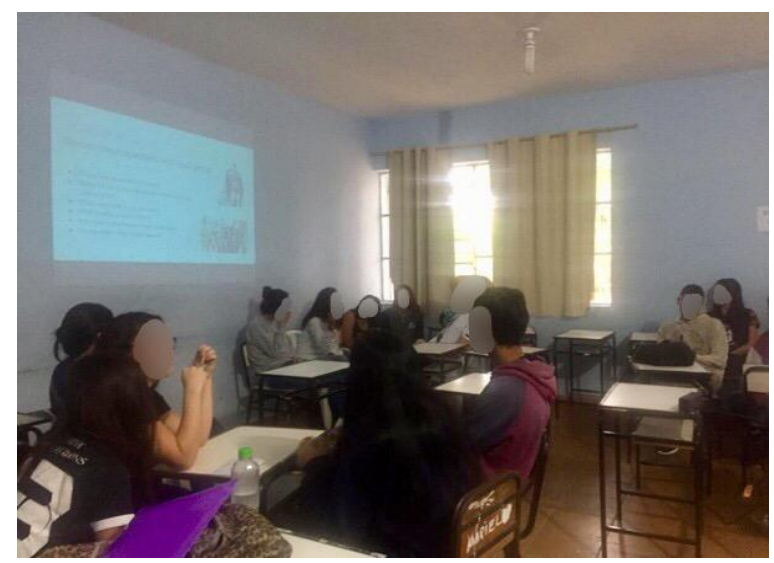

Fonte: os autores, 2018.

Após socialização das discussões, a turma assistiu ao trailer do blockbuster "Pantera Negra" e, em seguida, houve um momento de reflexão sobre o vídeo, objetivando discutir, principalmente, a forma como os personagens negros são representados na ficção - como, por exemplo, o fato do herói protagonista do filme ser um homem negro e a presença de guerreiras negras na sociedade fictícia, chamando atenção para a visibilidade dada à comunidade no longa. Por fim, os instrutores alertaram para a constante ausência de pessoas negras em papéis de evidência por falta de representatividade.

\subsection{TRABALHANDO O TEXTO TEÓRICO DE FORMA PARTICIPATIVA}

No segundo momento, inicialmente fizemos uma breve apresentação acerca da definição de representatividade, chamando atenção para a sub-representação de minorias na mídia televisiva, bem como em filmes, livros e outras produções artísticas. Entre os grupos minoritários discutidos, citamos, além das pessoas negras, também as mulheres, os LGBTs, pessoas gordas e pessoas com deficiências (PcDs). Em seguida, numa tentativa de tornar a parte expositiva mais participativa e propiciar a utilização do vocabulário - previamente introduzido -, cada aluno recebeu tiras de papel com partes do texto What exactly is Media Representation Anyway $?^{5}$, da autora e cinematógrafa americana Yasmina Tawil, com os parágrafos numerados e destacados para leitura e debates em

\footnotetext{
${ }^{4}$ Disponível em: 〈https://www.youtube.com/watch?v=xjDjIWPwcPU $>$.

${ }^{5}$ Disponível em: <https://arabfilminstitute.org/what-exactly-is-media-representation-anyway/>.
} 
grupo, seguidos de curtos momentos de socialização. $\mathrm{Na}$ primeira parte do texto, algumas das questões colocadas foram a importância da representatividade e de uma boa representação na mídia como forma de quebrar estereótipos e aumentar a autoestima de indivíduos de grupos distintos. Já na segunda parte, discutimos alguns dos equívocos presentes na maioria das representações midiáticas atuais que se dizem diversificadas. Para isso, utilizamos alguns elementos provocadores como a imagem a seguir:

Figura 2 - Propaganda controversa da GapKids, de 2016: possível exemplo de tokenismo.

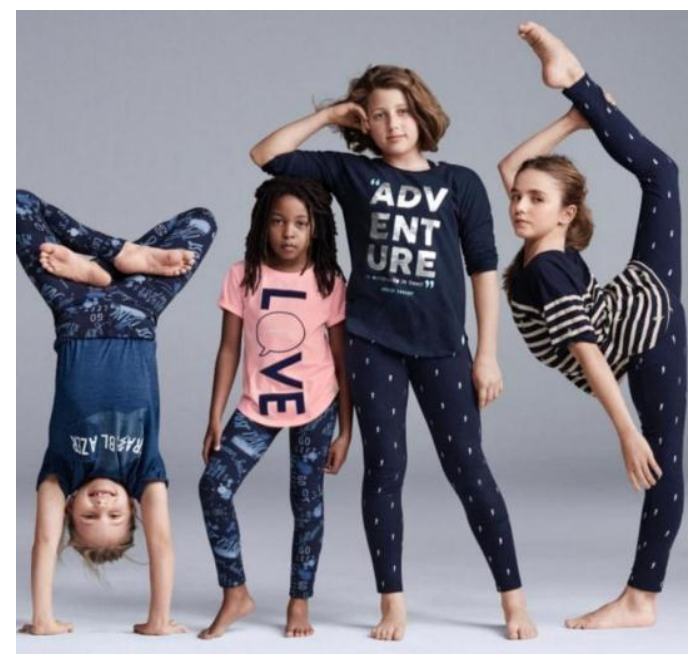

Fonte: 〈https://www.bbc.com/news/blogs-trending-35968787>. Acesso em: 4 jan. 2021.

Algumas das práticas discutidas nesta parte foram: o tokenismo, como ilustrado na figura acima - que consiste na representação de minorias de forma superficial, apenas como tentativa de parecer inclusivo, - e o typecasting - que se caracteriza pela recorrência de atores representando papéis estereotipados em produções diferentes, em função da sua etnia ou pelo sucesso daquele tipo de personagem no passado. Tais práticas, como problematizado pelos instrutores, reforçam a presença de uma representatividade defectiva na mídia, a qual distancia-se de representações verossímeis e que, como posto por Andrade (2020), opõem-se à pluralidade identitária humana.

\subsection{PROVOMENDO CONSCIETIZAÇÃO ATRAVÉS DE UM VÍDEO MOTIVADOR}

No terceiro momento, objetivamos trabalhar os efeitos do racismo estrutural na produção de brinquedos infantis que, no caso das bonecas negras, representaram apenas $6 \%$ das bonecas comercializadas em 2020 segundo levantamento feito pela campanha "Cadê Nossa Boneca", da organização Avante - Educação e Mobilização Social, número ainda menor que o de 2018, que foi 7\%. Para isso, trouxemos imagens que ilustram como a falta de representatividade em brinquedos 
pode afetar a autoestima de crianças negras, gerando internalização de ódio e sentimento de inferioridade, além da associação do negro ao negativo. Em seguida, os alunos assistiram a um vídeo intitulado Doll Test ${ }^{6}$ (Teste da Boneca, em português ), que ilustra tal efeito danoso. O teste, que é uma réplica do original criado pelos psicólogos Kenneth e Mamie Clark, nos anos 40, para estudar os efeitos da segregação racial em crianças afro-americanas, consiste em analisar a percepção racial de meninos e meninas negras de diferentes idades com a apresentação de duas bonecas, uma negra e outra branca, indagando sobre sua preferência. A Figura 3 ilustra tal experimento:

Figura 3 - O psicólogo Kenneth Clark observando uma criança negra em sua investigação.

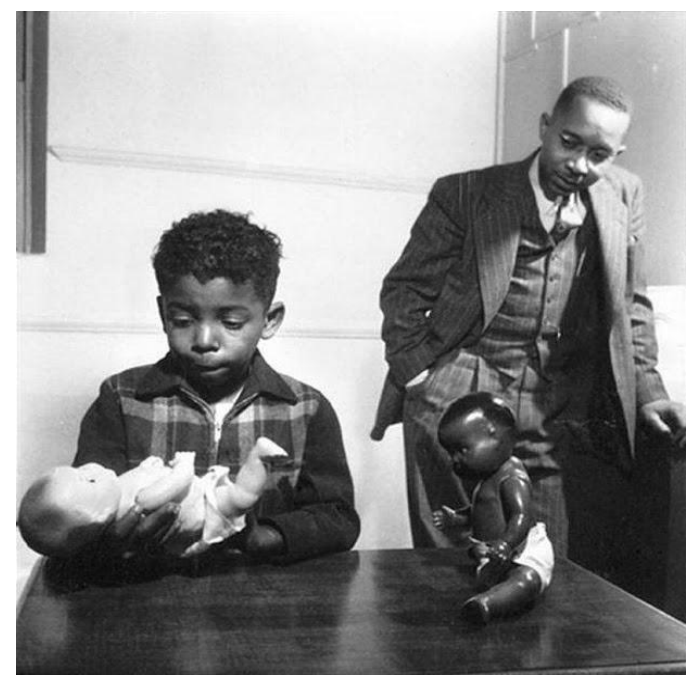

Fonte: <https://cutt.ly/2kqhIAW >. Acesso em: 4 jan. 2021.

O ensaio de Kenneth e Mamie Clark, como discutido em nossa aula, evidencia como o racismo sistêmico pode corromper a percepção inocente das crianças, sobretudo as negras, que, em sua maioria, acabam atribuindo características positivas à boneca branca e negativas à negra. Desta forma, o experimento psicológico demonstra o que Skerrett (2011 apud FERREIRA, 2014) afirma ser a interferência da raça nas relações sociais. No caso do vídeo, percebe-se, com clareza, que a supremacia branca reforçada pela mídia consolida a naturalização de uma visão corrompida de ideal de beleza eurocêntrico baseada na discriminação de traços negros, explicitando, ainda, conforme atesta Guinier (2004 apud FERREIRA, 2014), como as dinâmicas raciais representam um instrumento de domínio social e perpetuação de preconceitos.

\subsection{CONCLUINDO A AULA DE FORMA REFLEXIVA POR MEIO DE UMA DINÂMICA}

\footnotetext{
${ }^{6}$ Disponível em: 〈https://www.youtube.com/watch?v=QRZPw-9sJtQ $>$.
} 
Por último, objetivando promover um momento de reflexão de forma lúdica e sinestésica, foi feita uma dinâmica que exigia movimentação na sala e posicionamento. Para isso, foram selecionadas previamente algumas afirmações polêmicas de cunho racial em inglês, como You're not a racist if you have black friends (Você não é racista se tem amigos negros) e All lives matter not just black ones (Todas as vidas importam - não só as negras), que geralmente são usadas por pessoas racistas para mascarar e justificar seus preconceitos. Nas paredes da sala, foram colados cartazes indicando diferentes graus de opinião, como strongly agree (concordo fortemente), strongly disagree (discordo fortemente), partly agree (concordo parcialmente) e partly disagree (discordo parcialmente). À medida que cada frase era lida por um dos instrutores, os alunos deveriam se mover em direção ao cartaz que melhor representasse sua concordância/discordância com a declaração em questão.

Cabe ressaltar que o intuito dessa atividade não foi o de criticar ou expor os alunos por suas opiniões e/ou convicções consideradas equivocadas pelo grupo, mas sim apontar para a problemática presente nas afirmativas trazidas, instruindo-os acerca das formas de preconceito velado por trás de cada uma delas. Desta maneira, nossa dinâmica mostrou-se alinhada à proposta do LRC, pois, segundo Ferreira (2014), a atividade objetivou desenvolver a capacidade dos alunos de interpretar códigos e comportamentos racistas do dia a dia e eliminá-los através da reeducação.

Ao fim da aula, não pudemos deixar de notar, por meio do entusiasmo e inquietação dos estudantes, a satisfação da turma com a temática discutida e com as atividades propostas, principalmente durante a dinâmica final, que possibilitou a observação do exercício crítico colaborativo entre os alunos através do compartilhamento de pontos de vista diferentes e do posicionamento de forma democrática. Além disso, houve ainda pequenos momentos de agradecimentos e retorno positivo da turma, que fizeram toda a diferença, e que nos ajudaram a sair da sala com a sensação de dever cumprido.

\section{RESULTADOS E DISCUSSÕES PÓS-INTERVENÇÃo}

As escolhas didáticas, os recursos pedagógicos, os materiais selecionados e a própria ordenação das etapas da aula possibilitaram a observação de resultados interessantes ao longo e ao fim de nossa experiência. Desde o warm-up à dinâmica final, pudemos notar o interesse dos alunos e abertura à argumentação com os instrutores e colegas. Além disso, durante a aula, houve diversos momentos de comentários, réplicas e exercício da criticidade que corroboram com a ideia presente na BNCC de uma educação em prol da ação e posicionamento crítico na sociedade. 
Pudemos observar também, com base nas opiniões e falas dos estudantes, como as discussões e os materiais selecionados (principalmente, o vídeo "Teste da Boneca" e a dinâmica final) tornaram visível aos olhos dos alunos o quanto a raça influencia a experiência social, cumprindo, portanto, nosso propósito de prática do LRC. Em especial, como já discutido anteriormente, o Teste da Boneca evidencia o que Almeida (2017 apud SANTOS, 2020) chama de “racialização das relações", visto que, através do vídeo, fica claro que as tensões raciais em nossa sociedade repousam na cristalização de práticas racistas e discriminatórias desde a tenra idade.

Ademais, cabe ressaltar que, ainda que nosso interesse primário fosse o ensino da língua inglesa, em nenhum momento nos ativemos à correção excessiva de equívocos gramaticais ou de pronúncia, às hesitações dos alunos ao falar o idioma estrangeiro ou à preferência em se expressar na língua materna. A abordagem pedagógica do LRC utilizada em nossa aula, conforme afirmam Troyna et Carrington (1990 apud SANTOS, 2020), promove a igualdade através da educação, e prioriza a relevância social e a contextualização do aprendizado do inglês em oposição a um ensino linguístico destituído de uma aplicação significativa, sem propósitos sociocomunicativos claros.

\section{CONSIDERAÇÕES FINAIS}

Após a conclusão satisfatória de nossa proposta, reiteramos que se faz extremamente necessária a conscientização dos alunos através de práticas de LRC, como a discutida neste trabalho, não só nas aulas de linguagens, mas também em outras disciplinas. Acreditamos que, para o ensino do inglês, o formato de aula temática se mostrou muito eficiente no desenvolvimento da criticidade e da compreensão dos direitos das minorias. Além disso, ponderamos que as aulas de línguas devem transcender o ensino de aspectos estruturais, visando formar, não só alunos com habilidades linguísticas, mas cidadãos conscientes de temas sociais e que respeitem as diferenças.

Todavia, ao longo do desenvolvimento desta proposta de intervenção, não pudemos deixar de pensar também sobre o avanço de movimentos político-partidários, nos últimos anos, na forma de projetos de lei que se dizem a favor da educação e contra a "doutrinação ideológica" nas salas de aula - como é o caso do "Escola sem partido", que põe em xeque a função social da escola e o exercício de um ensino democrático. Ademais, refletimos sobre o crescente corte de verbas na educação que, além de visar o sucateamento das escolas públicas, ameaçam projetos tão especiais como o PIBID, que contribuem positivamente para possibilitar a oferta de um ensino gratuito de qualidade. 


\section{REFERÊNCIAS}

BRASIL. Lei de Diretrizes e Bases da Educação Nacional. Lei número 9394, 20 dez. 1996. Disponível em: http://www.planalto.gov.br/ccivil_03/leis/2003/110.639.htm. Acesso em: 4 jan. 2021.

BRASIL. Ministério da Educação/Secretaria de Educação Básica. Base Nacional Comum Curricular (BNCC). Educação é a base. Brasília: MEC/SEB/CNE, 2018. Disponível em: http://basenacionalcomum.mec.gov.br/abase/\#medio/a-area-de-linguagens-e-suas-tecnologias.

Acesso em: 4 jan. 2021.

FERREIRA, A. J. Educação linguística crítica e identidades sociais de raça. In: PESSOA, R. R. et al (Org.). Perspectivas críticas de educação linguística no Brasil: trajetórias e práticas de professoras(es) universitárias(os) de inglês. 1 Ed. São Paulo: Pá de Palavra, 2018, p. 39-46.

FERREIRA, A. J. Teoria racial crítica e letramento racial crítico: Narrativas e contranarrativas de identidade racial de professores de línguas. Revista da Associação Brasileira de Pesquisadores/as Negros/as (ABPN), [S.1.], v. 6, n. 14, p. 236-263, out. 2014.

SANTOS, A. C. R. dos. Representação do negro na mídia: a importância do letramento racial para aulas de inglês. São Cristóvão, 2020. Monografia (licenciatura em Letras Português-Inglês) Departamento de Letras Estrangeiras, Centro de Ciências Humanas, Universidade Federal de Sergipe, São Cristóvão, SE, 2020.

\section{OUTRAS FONTES CONSULTADAS:}

ANDRADE, R. Representatividade: o que isso significa?. Politize!, 2020. Disponível em: https://www.politize.com.br/representatividade/. Acesso em: 6 jan. 2021.

MORENO, A. C. Número de alunos negros reprovados nas escolas do Brasil é duas vezes maior que o de brancos, diz UNICEF. G1, 2019. Disponível em: https://g1.globo.com/educa cao/noticia/2019/10/31/alunos-pretos-representam-39percent-do-total-das-matriculas-e-58percentdo-total-de-reprovados-diz-unicef.ghtml. Acesso em: 4 jan. 2021.

SEGUNDO dados, apenas $6 \%$ das bonecas produzidas são negras. Metrópoles, Brasília, 5 nov. 2020. Disponível em: https://www.metropoles.com/dino/segundo-dados-apenas-6-das-bonecasproduzidas-sao-negras. Acesso em: 27 jan. 2021. 